\title{
Virale Infektionen des zentralen Nerven- systems und Neuro-Aids: was ist neu?
}

Matthias Maschke

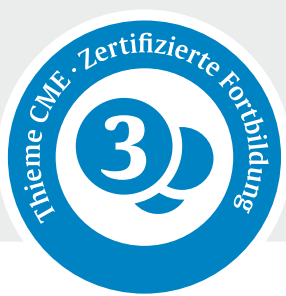

Virale Enzephalitiden sind in Westeuropa vergleichsweise selten, gehören aber weltweit zu den häufigsten Erkrankungen, die zu einem Leben mit Behinderung führen [1,2]. Die Differenzialdiagnose bezüglich der Erreger ist einerseits sehr weitreichend, andererseits ist die rechtzeitige Diagnose und rascher Beginn einer Therapie für das Outcome unerlässlich.

\begin{tabular}{|c|c|c|c|}
\hline \multicolumn{4}{|c|}{ ABKÜRZUNGEN } \\
\hline AAN & American Academy of Neurology & HSV & Herpes-simplex-Virus \\
\hline ADEM & akute disseminierte Enzephalomyelitis & HTLV & humane T-Zell-lymphotropes Virus \\
\hline \multirow[t]{2}{*}{ ANPD } & HIV-assoziiertes neuropsychologisches & Ig & Immunglobulin \\
\hline & $\begin{array}{l}\text { Defizit } \\
\text { antiretroviral toxische Neuropathie }\end{array}$ & IRIS & $\begin{array}{l}\text { inflammatorisches Immunrekonstitu- } \\
\text { tionssyndrom }\end{array}$ \\
\hline BIPLED & $\begin{array}{l}\text { bilaterale periodische lateralisierte } \\
\text { epileptiforme Entladung }\end{array}$ & JC-Virus & $\begin{array}{l}\text { humanes Polyomavirus 2, JC-Polyoma- } \\
\text { virus, John-Cunningham-Virus }\end{array}$ \\
\hline CART & antiretrovirale Kombinationstherapie & LCM & lymphozytäre Choriomeningitis \\
\hline cCT & $\begin{array}{l}\text { kraniale Computertomografie } \\
\text { (Schädel-CT) }\end{array}$ & $\begin{array}{l}\text { MNCD } \\
\text { MRN }\end{array}$ & $\begin{array}{l}\text { HIV-assoziierte neurokognitive Defizit } \\
\text { Kernspin-Spektroskopie }\end{array}$ \\
\hline cMRT & kraniales MRT & NAW & Notarztwagen \\
\hline CMV & Zytomegalievirus & NMDA & N-Methyl-D-Aspartat \\
\hline \multicolumn{2}{|c|}{ CPE-Score CNS Penetration Effectiveness-Score } & NSE & neuronenspezifische Enolase \\
\hline CRP & C-reaktives Protein & PCR & Polymerase Chain Reaction \\
\hline DSP & distal symmetrische Polyneuropathie & PLED & periodische lateralisierte epileptiforme \\
\hline DSS & Dengue-Schocksyndrom & & Entladung \\
\hline EBLV & European Bat Lyssa-Virus & PML & progressive multifokale Leukoenzepha- \\
\hline EBV & Epstein-Barr-Virus & & lopathie \\
\hline \multirow[t]{2}{*}{ ECHO } & Akronym: enteric, cytopathic, human, & RKI & Robert Koch-Institut \\
\hline & orphan & RNA & Ribonukleinsäure \\
\hline EEG & Elektroenzephalografie & SIADH & Syndrom der inadäquaten ADH (antidiu- \\
\hline EV71 & Enterovirus 71 & & retisches Hormon)-Sekretion= Schwartz- \\
\hline FDA & Food and Drug Administration (der USA) & & Bartter-Syndrom \\
\hline FLAIR & Fluid Attenuated Inversion Recovery & STIKO & Ständige Impfkommission des Robert \\
\hline FSME & Frühsommermeningoenzephalitis & & Koch-Instituts \\
\hline GABA & Gamma-Aminobuttersäure & SWI & susceptibility-weighted imaging \\
\hline Gd & Gadolinium & VSBV-1 & variegated Squirrel-derived Bornavirus-1 \\
\hline HAD & HIV-assoziierte Demenz & VZV & Varicella-zoster-Virus \\
\hline HAND & HIV-associated neurocognitive Disorders & ZNS & zentrales Nervensystem \\
\hline HHV & humanes Herpesvirus & ZVK & zentraler Venenkatheter \\
\hline HIV & humanes Immundefizienzvirus & & \\
\hline
\end{tabular}

Durch sogenannte Emerging Viruses wie West-Nil-Virus, Usutu-Virus, Zika-Virus oder Dengue-Virus - durch den Klimawandel in unseren Breiten inzwischen anzutreffende Viren - ist die Differenzialdiagnose nicht einfacher geworden. Dazu kommt, dass sich die Situation bezüglich Neuinfektionen mit HIV nur wenig entspannt hat und hier die neurologische Mitbeteiligung nach wie vor eine wichtige Rolle spielt. 


\section{Merke}

Insofern sind vor diesem Hintergrund Kenntnisse zu viralen Infektionen des ZNS im klinischen Alltag unabdingbar, um rasche und richtige Entscheidungen für die Initiierung der notwendigen Therapie treffen zu können.

\section{Epidemiologie}

Epidemiologische Studien zeigen eine Inzidenz der viralen Enzephalitis von 0,07 bis 12,6/100 000 Einwohner pro Jahr [1]. Bei Kindern wie auch bei älteren Personen über 65 Jahren ist die Inzidenz jedoch deutlich höher:

- Kinder < 1 Jahr: 10,7/100 000 Einwohnern pro Jahr,

- Personen > 65 Jahre: 8,1/100000 Einwohnern pro Jahr.
Die häufigsten Enzephalitiden des Erwachsenenalters in Europa sind Herpes-simplex-Virus (HSV) Typ 1, Varicella-zoster-Virus (VZV), Epstein-Barr-Virus (EBV), Mumps-, Masern- und Enteroviren wie Coxsackie A und B und ECHO-Virus [3,4]. Die Inzidenz der HSVTyp-1-Enzephalitis ist dabei seit Jahren gleichbleibend bei etwa 1-4 Fälle/1 Mio. Einwohner pro Jahr.

Weltweit gesehen ist die Japan-Enzephalitis mit ca. 50000 Fällen pro Jahr die häufigste Enzephalitis. Es gibt starke saisonale wie auch regionale Schwankungen, was gerade die Masern-Epidemie der letzten Jahre aufgrund von Ressentiments gegen Impfungen speziell in urbanen Bereichen wie Berlin deutlich machte. Die Infektion mit Influenza A und B kann ebenfalls zu einer Enzephalitis führen ( $\mathbf{T a b} \mathbf{1} \mathbf{1})$.

- Tab. 1 Humanpathogene Viren, die eine Meningoenzephalitis verursachen können (Häufigkeitsangaben aus [1, 3, 4]).

\begin{tabular}{|c|c|c|c|}
\hline Familie & Gattung & Erbgut & Anteil an Enzephalitis \\
\hline \multicolumn{4}{|l|}{ Herpesviridae } \\
\hline & Herpes-simplex-Virus Typ 1 und Typ 2 & DNA & $\begin{array}{l}11-42 \% \text { (davon } 90 \% \text { HSV }-1 \text {, } \\
10 \% \text { HSV }-2 \text { ) }\end{array}$ \\
\hline & Varicella-zoster-Virus & DNA & $15-27 \%$ \\
\hline & Zytomegalievirus & DNA & \\
\hline & Epstein-Barr-Virus & DNA & \\
\hline & humanes Herpesvirus Typ 6 (selten auch Typ 7) & DNA & \\
\hline Orthomyxoviridae & Influenzavirus Typ A (v. a. H1N1) und B & RNA & $7 \%$ \\
\hline Picornaviridae & $\begin{array}{l}\text { Enteroviren } \\
\text { " Coxsackie-A-, -B-Virus, } \\
\text { - ECHO-Viren } \\
\text { - Poliomyelitisviren } \\
\text { - Enterovirus 68-72 }\end{array}$ & RNA & $11 \%$ \\
\hline \multicolumn{2}{|l|}{ Arboviridae } & RNA & \\
\hline - Togaviridae & $\begin{array}{l}\text { Flaviviren: } \\
\text { - Murray-Valley-Virus } \\
\text { - St.-Louis-Enzephalitisvirus } \\
\text { - Japan-Enzephalitisvirus } \\
\text { - West-Nil-Virus, Frühsommermeningoenzephalitis } \\
\text { (FSME)-Virus } \\
\text { - Usutu-Virus } \\
\text { - Rubiviren (Rötelnvirus) }\end{array}$ & RNA & \\
\hline - Bunyaviridae & California-Enzephalitisvirus & RNA & \\
\hline - Arenaviridae & lymphozytäres Choriomeningitis (LCM)-Virus & RNA & \\
\hline - Rhabdoviridae & Lyssavirus (Tollwutvirus, EBLV-1 und 2) & RNA & \\
\hline Bornaviridae & variegated Squirrel-derived Bornavirus-1 (VSBV-1) & RNA & \\
\hline Paramyxoviridae & $\begin{array}{l}\text { Masernvirus } \\
\text { Mumpsvirus }\end{array}$ & RNA & \\
\hline Adenoviridae & Mastadenovirus & DNA & \\
\hline
\end{tabular}




\section{FALLBEISPIEL}

Fall 1

Ein 56-jähriger Lehrer wird über den Rettungsdienst in die Notaufnahme gebracht. Zu Hause wie auch im NAW habe er zweimalig generalisierte Anfälle erlitten. Bei Aufnahme zeigt sich ein somnolenter Patient mit rechtsseitiger leichtgradiger Hemiparese und Orientierungsstörungen. Die Temperatur beträgt $>39^{\circ} \mathrm{C}$.

- Labor:

- Na 135,

- Leukozyten 6,7/nl,

- keine CRP-Erhöhung.

In der cCT ( Abb. 1 links) zunächst hyperdense Struktur links temporopolar.

Empirische Gabe von Aciclovir $3 \times 10 \mathrm{mg} / \mathrm{kgKG}$, Ceftriaxon $4 \mathrm{~g}$ und Ampicillin $3 \times 5 \mathrm{~g}$ iv. Bei fehlender Besserung am Folgetag cMRT ( $\triangleright$ Abb. 1 Mitte u. rechts) sowie erneute Lumbalpunktion. In der CMRT dann typische Veränderungen in der T2WI sowie FLAIR links temporopolar mit V.a. auf eine HSVEnzephalitis. In der Lumbalpunktion dann passend HSV-PCR positiv. Über die folgenden 7 Tage langsame Besserung und Verlegung in die Rehabilitation.

- Liquor:

- Protein $124 \mathrm{mg} / \mathrm{dl}$,

- Zellzahl 211/ul, 95\% Lymphozyten,

- Laktat normal,

- PCR auf HSV, VZV, CMV zunächst negativ.
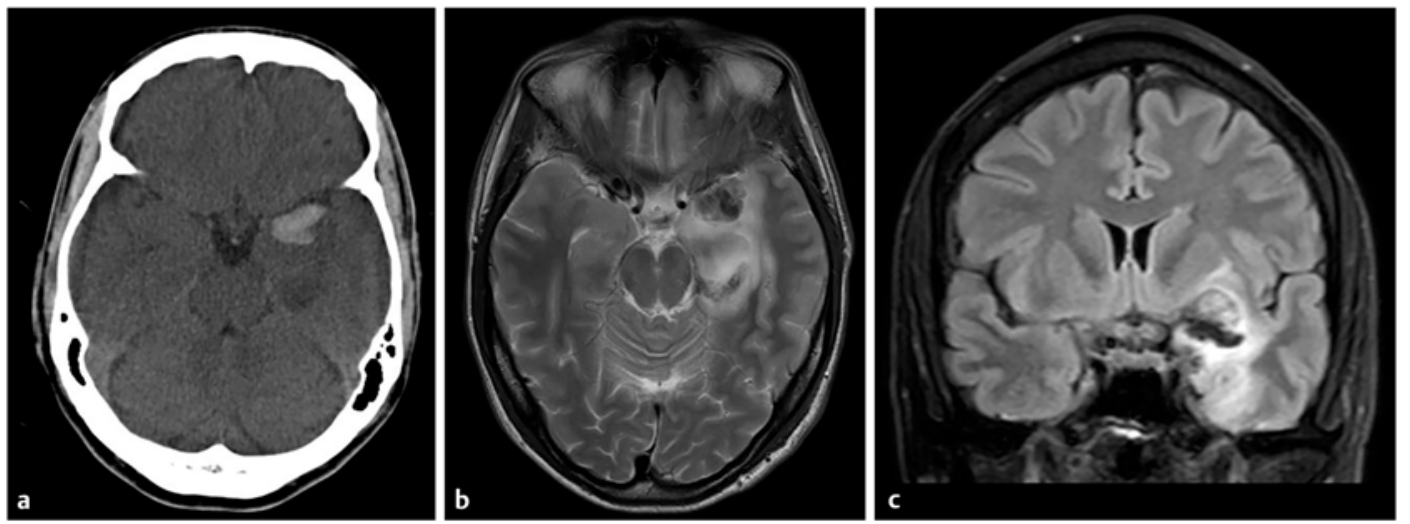

- Abb. 1 Im cCT (links) hyperdense Struktur links temporopolar im Sinne einer intrazerebralen Blutung. Im cMRT in der T2WI (Mitte) wie auch in der FLAIR (rechts) typisches Bild einer hämorrhagischen Temporallappenenzephalitis passend zu einer HSV-Enzephalitis.

Wichtig in der Einschätzung epidemiologischer Daten ist, dass selbst mit den heutigen sensitiven PCRMethoden in 50-75\% der Fälle der Erreger weder aus dem Liquor noch aus dem Blut identifiziert werden kann $[1,3,4]$.

Zu beobachten ist gerade aus neurologischer Sicht die durch den Klimawandel begünstigte Ausbreitung von Emerging Viruses wie Dengue-Viren, West-Nil Virus, Usutu-Virus, Zika-Virus und Japan-Enzephalitisvirus. Weltweit sind diese Infektionen in den letzten 3 Jahren deutlich häufiger und gerade auch in Europa zunehmend. So kam es nach aktuellen Zahlen des Robert Koch-Instituts z. B. zu zunehmenden Erkrankungen mit Flaviviren wie z.B. dem Dengue-Virus. Während 2001 nur 60 Fälle mit Dengue-Fieber dem Robert Koch-Institut (RKI) gemeldet wurden, waren es 2015722 Fälle, im
Jahr 2019 bereits zur Hälfte des Jahres 664 Fälle. Ähnliche Entwicklungen gibt es für die anderen Flaviviren wie Zika-Virus, West-Nil-Virus oder Usutu-Virus. Erstmalig wurden 2019 autochthone Infektionen mit West-Nil-Virus in Deutschland gemeldet.

Bezüglich der Neuinfektionsrate mit HIV ist nach Jahren des Anstiegs eher eine leicht rückläufige Tendenz zu erkennen. Die Neuinfektionsrate für HIV sank laut Zahlen des RKI von 2800 im Jahr 2015 auf 2400 im Jahr 2018 [5]. 
FAZIT

Die häufigsten Erreger einer Enzephalitis bei Erwachsenen sind in Deutschland weiterhin die Herpesviridae, allen voran das Herpes-simplexVirus Typ 1.Zunehmend sollten jedoch auch Emerging Viruses (West-Nil Virus, Usutu-Virus, Dengue-Virus, Zika-Virus) beachtet werden.

\section{Klinische Symptome}

\section{Klinische Symptome bei Herpesviridae, Picornaviridae, Orthomyxoviridae, Paramyxoviridae und Flaviviren}

Das klinische Erscheinungsbild viraler Infektionen des ZNS ist nicht spezifisch genug, um darüber eine präzise diagnostische Zuordnung zu erlauben [2]. Selten lässt das gleichzeitig auftretende Exanthem wie bei VZV oder Masern bereits eine klinische Diagnose zu. Eine Diarrhöe weist auf eine Enteroviruserkrankung, ausgeprägte Myalgien auf eine Flavivirusinfektion (v.a. Dengue-Virus) hin.

Die virale Meningitis ist mindestens doppelt so häufig wie die virale Enzephalitis oder Meningoenzephalitis. Die führenden klinischen Symptome der akuten viralen Meningitis sind Kopfschmerz, Fieber und meningeale Reizung mit Nackendehnungszeichen. In variabler Ausprägung können Übelkeit, Erbrechen, Photophobie und Bewusstseinsstörungen hinzutreten. Neurologische Fokalzeichen sind als Hinweis auf eine Beteiligung des Hirnparenchyms zu werten. Milde radikuläre Symptome oder umschriebene Hirnnervenausfälle werden jedoch gelegentlich bei Meningitiden beobachtet.

Die virale Enzephalitis ist eine Infektion des Hirnparenchyms und wird oft von Zeichen der meningealen (Meningoenzephalitis) oder spinalen Beteiligung (Enzephalomyelitis) begleitet. Bisweilen treten insbesondere bei Flaviviren wie dem West-Nil-Virus oder Usutu-Virus auch radikuläre Symptome hinzu (z. B. Enzephalomyeloradikulitis). Meist erleben die Patienten ein kurzes Prodromalstadium mit Fieber, Kopfschmerz mit oder ohne Meningismus, Photophobie, Abgeschlagenheit, Übelkeit oder Erbrechen, das typischerweise gefolgt wird von qualitativen oder quantitativen Bewusstseinsstörungen, einer neurologischen Fokalsymptomatik und häufig auch epileptischen Anfällen.

Zum Zeitpunkt der Aufnahme im Krankenhaus sind die häufigsten Symptome einer durch Herpesviridae verursachten Enzephalitis: Fieber, Persönlichkeitsänderung und Aphasie, während eine Hemiparese nur in 38\% der Fälle gefunden wird [2,6] (s. > Tab.2). Fokale oder generalisierte Anfälle treten bei 7-11\% der Patienten auf.
Die Bewusstseinsstörung kann bis zum Koma fortschreiten und begleitet sein von Zeichen des zunehmenden Hirndruckes. Ein SIADH oder Diabetes insipidus können ebenso wie autonome Störungen im Gefolge einer viralen Enzephalitis auftreten.

Die Symptome einer Erkrankung mit Flaviviren präsentieren sich dagegen different. Bei einer Infektion mit West-Nil-Virus verläuft die Infektion in $60 \%$ asymptomatisch, nur ca. $5 \%$ werden korrekt diagnostiziert. Nach einer Inkubationszeit von 2-14 (selten bis zu 21 Tage) kommt es zu einem makulopapulösen Exanthem ohne Pruritus mit Aussparung der Hände und Sohlen. In $1 / 150$ bis $1 / 2$ Fällen sind die Infektionen neuroinvasiv. Es kommt dann entweder zu einer blanden Meningitis, zu einer Enzephalitis oder zu schlaffen, Poliomyelitisähnlichen Lähmungen [7].

Bei der West-Nil-Virus-Enzephalitis sind wie auch bei anderen Flaviviren (Japan-Enzephalitisvirus, Usutu-Virus) Symptome einer medialen Enzephalitis mit Beteiligung des Thalamus und des Hirnstamms (im Gegensatz zur limbischen Enzephalitis bei Herpesviridae) typisch. Dazu gehören

- ein ausgeprägter Haltetremor der Hände,

- extrapyramidal-motorische Symptome,

- Myoklonien der Hände und Gesicht v. a. im Schlaf und

- seltener eine Ataxie, Anfälle und ein erhöhter Hirndruck.

Bei der Infektion mit Dengue-Virus kann es v. a. bei der zweiten Infektion im Leben eines Patienten zum Dengue-Schocksyndrom (DSS, Knochenbrecherfieber) kommen. Nach einer Inkubationszeit 3-7 Tage entwickelt sich die Dengue-Trias bestehend aus einer Temperatur von $40^{\circ} \mathrm{C}$, einem Exanthem sowie extreme Myalgien. Die Erkrankung kann hämorrhagisch mit einer deutlichen Thrombozytopenie, disseminierten Petechien und inneren Blutungen verlaufen. Zu diesem Zeitpunkt sind neurologische Symptome durch Enzephalitis bis hin zum Koma, intrazerebralen Blutungen

- Tab. 2 Häufigkeiten von Symptomen einer Enzephalitis durch Herpesviridae [2,6].

\begin{tabular}{|l|c|}
\hline Symptom & Häufigkeit \\
\hline Fieber & $92 \%$ \\
\hline Persönlichkeitsänderung & $85 \%$ \\
\hline Aphasie & $76 \%$ \\
\hline Hemiparese & $38 \%$ \\
\hline Fokale oder generalisierte Anfälle & $7-11 \%$ \\
\hline $\begin{array}{l}\text { andere Symptome: Diabetes insipidus, } \\
\text { SIADH }\end{array}$ & $<10 \%$ \\
\hline
\end{tabular}


und Krampfanfällen möglich. Die Letalität beträgt 1-5 $\%$, v. a. durch innere Blutungen.

Eine reine Myelitis als viral bedingte Erkrankung ist selten. Die häufigsten Erreger akuter viraler Myelitiden in Europa sind Coxsackie-A- und -B-Viren, ECHO-Viren, VZV und FSME-Virus. Bei Menschen mit HIV können akute Myelitiden durch HSV und/oder CMV sowie VZV hervorgerufen werden. Sehr selten findet sich CMV auch als Ursache einer Myelitis bei immunkompetenten Patienten [8]. Andere Viren, die als Auslöser einer Myelitis identifiziert wurden, sind Influenzavirus Typ A, Rötelnvirus, und das West-Nil-Virus. Möglicherweise können auch Hepatitis C (über autoimmunvermittelte Mechanismen), Hepatitis E und HHV-7 zu Myelitiden führen.

Zudem ist das humane T-Zell-lymphotrope Virus Typ 1 (HTLV-1) als auslösendes Virus für die tropische spastische Paraparese bzw. HTLV 1-assoziierte Myelopathie nachgewiesen worden. Da das Virus v.a. in tropischen Ländern vorkommt, muss an HTLV-1 v.a. bei Patienten mit entsprechender Reiseanamnese gedacht werden.

Als ebenfalls seltene isolierte Symptomatik ist v. a. bei Kindern eine Zerebellitis möglich. Diese führt zu zerebellären Symptomen mit Rumpf- und Extremitätenataxie, zerebellärer Dysarthrie und einer ausgeprägten Stand- und Gangataxie. Aufgrund der Schwellung in der hinteren Schädelgrube und der möglichen Mitbeteiligung des Hirnstamms kann es zu Hirnnervenausfällen, Singultus und einem zunehmenden Hirndruck kommen. Typischerweise sind EBV, VZV, HSV Typ 2 sowie bei immuninkompetenten Patienten JC-Virusinfektionen ursächlich [9]. Neuerdings werden aber auch Zerebellitiden bei Dengue-Virus oder auch West-NilVirus und Influenza-A- oder -B-Infektionen beobachtet.

\section{FAZIT}

Bei der viralen Enzephalitis gibt es keine spezifischen Symptome. Kortikale Fokalsymptome mit Persönlichkeitsänderung, Aphasie oder auch epileptische Anfälle lassen eher an eine Infektion mit Herpesviridae denken. Extrapyramidalmotorische Symptome und Myoklonien sowie Tremor können ein Hinweis auf eine Infektion mit Flaviviren sein.

\section{FALLBEISPIEL}

\section{Fall 2}

Eine 30-jährige Patientin wird kommt mit extremsten Muskelund Gelenkschmerzen sowie einer Temperatur von $39,2{ }^{\circ} \mathrm{C}$ in die Notaufnahme gebracht. Internistisch finden sich ein druckdolentes Abdomen, ein flächiges stammbetontes Exanthem sowie disseminierte Petechien. Neurologisch zeigen sich ein Meningismus, gesteigerte Muskeleigenreflexe sowie im weiteren Verlauf eine zunehmende Somnolenz. Im Labor findet sich eine Leukozytose von 16000/ $\mathrm{\mu l}$, ein CRP von $12 \mathrm{mg} / \mathrm{dl}$ ohne begleitendes Procalcitonin sowie eine Thrombozytopenie von $88000 / \mu l$. Bildgebend lässt sich lediglich eine geringe generalisierte Schwellung nachweisen. Im Liquor findet sich eine leichte lymphozytäre Pleozytose von 153 Zellen/ $\mu$ l ohne Protein- oder Laktaterhöhung.

Aus der Fremdanamnese ist zu erfahren, dass die Patientin vor 7 Tagen an der Cote d'Azur Urlaub gemacht hatte. Dort habe sie zahlreiche Mückenstiche erlitten.

Im weiteren Verlauf wird die Patientin symptomorientiert intensivmedizinisch behandelt. Nach 5 Tage bessern sich die Symptome allmählich, und die Patientin kann nach 14 Tagen entlassen werden.

Retrospektiv bestätigte sich die Verdachtsdiagnose eines Dengue-Schocksyndroms nach Erhalt des Befundes aus dem Fremdlabor von positiven IgM- und IgG-Antikörpern gegen Dengue-Virus.

\section{Klinische Symptome bei HIV}

Bei HIV ist die Beteiligung des ZNS sowohl durch das Virus selbst, aber auch durch opportunistische Infektionen möglich. In der Ära vor der Einführung der modernen antiretroviralen Kombinationstherapien (CART) 1996 korrelierte die Prävalenz neurokognitiver Defizite HIV-Infizierter mit dem Abfall CD4 + -positiver Lymphozyten. 20-30\% der Betroffenen waren am Ende ihres Lebens dement. Die „klassische“ HIV-assoziierte Demenz ist durch motorische, kognitive und emotionale Defizite charakterisiert, die Patienten zeigen dagegen seltener eine Aphasie oder Apraxie.

Heutzutage ist die Symptomausprägung durch die sehr gut wirksame cART deutlich milder [10]. Es stehen meist kognitive Einbußen im Vordergrund. Trotz der modernen antiretroviralen Kombinationstherapien treten bei HIV-Infizierten auch heute noch neurokognitive Störungen auf, die seit einer Konsensuskonferenz 2005 in Frascati unter dem Begriff „HAND“ (HIV-associated neurocognitive Disorders) zusammengefasst bzw. als „Frascati-Kriterien“ bezeichnet werden [11]. Man unterscheidet drei Stufen:

- das HIV-assoziierte neuropsychologische Defizit (ANPD),

- das milde HIV-assoziierte neurokognitive Defizit (MNCD) und 
- Tab.3 AAN-Definition der HIV-assoziierten neurokognitiven Erkrankungen (HAND) [11].

\begin{tabular}{|c|c|c|c|c|}
\hline Einteilung & $\begin{array}{l}\text { Keine vor- } \\
\text { bestehende } \\
\text { Ursache }\end{array}$ & Kein Delir & $\begin{array}{l}\text { Erworbenes Defizit } \\
\text { in mindestens } \\
2 \text { kognitiven Domänen }\end{array}$ & $\begin{array}{l}\text { Behinderung } \\
\text { im Alltag }\end{array}$ \\
\hline asymptomatisches neuropsychologisches Defizit (ANPD) & ja & ja & ja & nein \\
\hline mildes neurokognitives Defizit (MNCD) & ja & ja & ja & wenig \\
\hline HIV-assoziierte Demenz & ja & ja & immer & schwer \\
\hline
\end{tabular}

- die HIV-assoziierte Demenz (HAD), denen bestimmte Definitionskriterien zugrunde liegen ( $\triangleright$ Tab. 3).

\section{Merke}

Das periphere Nervensystem ist eine der häufigsten HIV-assoziierten Organbeteiligungen.

Dabei steht die klassische, distal-symmetrische HIV-assoziierte Polyneuropathie weiterhin im Vordergrund. Es treten jedoch vermehrt immunogen vermittelte Neuropathien oder Myopathien auf. Das zweite Spektrum umfasst neurotoxische Polyneuropathien oder auch Myopathien durch den langjährigen Einsatz antiretroviraler Substanzen. Distal symmetrische sensible Defizite bzw. Reizsymptome stellen das häufigste Symptom HIV-Infizierter dar. Die häufigste zugrunde liegende Ursache ist eine direkt HIV-assoziierte distal symmetrische Polyneuropathie (HIV-DSP) oder eine antiretroviral toxische Neuropathie (ATN). Da einheitliche Diagnosekriterien fehlen und Menschen mit HIV-Erkrankung nicht an jedem Zentrum regelhaft neurologisch untersucht werden, schwanken die Angaben zur Prävalenz zwischen 30 und $60 \%$.

Opportunistische Infektionen bei HIV sind heutzutage deutlich seltener und spielen häufig bei der Erstpräsentation eine Rolle. Etwa ein Drittel der Infektionen tre-

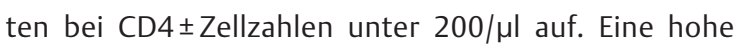
HI-Viruslast über 100000 RNA-Kopien/ml ist ein unabhängiger Risikofaktor für die Entstehung einer opportunistischen ZNS-Infektion. Gerade nach Initiierung einer CART kommt es häufig zu entzündlichen Erkrankungen des zentralen und peripheren Nervensystems. Die daraus resultierenden Erkrankungen werden inflammatorische Immunrekonstitutionssyndrome (IRIS) genannt. Diese IRIS sind extrem schwer von der eigentlichen opportunistischen Infektion abzugrenzen, sodass häufig ein diagnostisches und daraus resultierend therapeutisches Dilemma entsteht.

Die UK Collaborative HIV Cohort (CHIC) Study konnte wie auch andere Studien nachweisen $[12,13]$, dass die Inzidenz aller ZNS-Komplikationen inklusive der oppor- tunistischen Infektionen von 13,1/1000 Patientenjahre im Jahr 1996/1997 auf 1,0/1000 Patientenjahre im Jahr 2006/2007 deutlich abnahm. Die häufigsten Infektionen waren

- die progressive multifokale Leukoenzephalopathie (PML) (0,7/1000 Patientenjahre),

- die Toxoplasmaenzephalitis (0,4/1000 Patientenjahre) und

- die Kryptokokkenmeningitis (0,2/1000 Patientenjahre).

\section{FAZIT}

Die neurokognitiven Symptome sind heutzutage bei Menschen mit HIV-Erkrankung deutlich milder ausgeprägt und erfordern eine dezidierte neuropsychologische Untersuchung zur Detektion subklinischer Störungen. Opportunistische Infektionen haben in der Inzidenz drastisch nachgelassen und sind häufig Initialsymptom bei „Late Presenters“ ohne vorherige antiretrovirale Therapie.

\section{Autoimmune Erkrankungen infolge einer viralen Enzephalitis}

Seit mehreren Jahren mehren sich Berichte über paradoxe Verschlechterungen nach initialer Besserung einer viralen Enzephalitis. Insbesondere bei HSV-Typ1-Enzephalitiden kommt es bei einem Teil der Patienten zur Ausbildung einer autoimmunen Enzephalitis. Nach einer rezenten Studie aus Barcelona hatten 27\% aller Patienten nach HSV-Typ-1-Enzephalitis eine autoimmune Enzephalitis durch antineuronale Antikörper oder Antikörper gegen Oberflächenantigene (64\% NMDA-Rezeptor-Antikörper, 36\% andere Antikörper) [14]. Zumeist tritt die Erkrankung innerhalb von 2 Monaten nach HSV-Enzephalitis auf. Kinder < 4 Jahre haben die schlechteste Prognose. 
Tab. 4 Differenzialdiagnosen virale Enzephalitiden.

\begin{tabular}{|l|l|}
\hline bakterielle Infektion & Differenzialdiagnosen \\
\hline mykotische Infektion & Hirnabszess, Endocarditis lenta, Tuberkulose, Lues, Mycoplasma-pneumoniae-Infektion, Morbus Whipple \\
\hline parasitär Infektion & Kryptokokkose, Kandidose, Aspergillom \\
\hline autoimmune ZNS-Erkrankungen & Malaria, Toxoplasmose, Zystizerkose, Trichinose \\
\hline $\begin{array}{l}\text { akute disseminierte Enzephalomyelitis (ADEM), akute hämorrhagische Leukenzephalitis (Weston-Hurst-Enze- } \\
\text { phalitis), akuter Schub einer Enzephalomyelitis disseminata, autoimmune oder paraneoplastische limbische } \\
\text { Enzephalitis }\end{array}$ \\
\hline toxisch-allergisch & $\begin{array}{l}\text { Schwermetalle, nichtsteroidale Antiphlogistika (Ibuprofen, Naproxen), Azetylsalizylsäure, Sulfamethoxazol, } \\
\text { Trimethoprim, Isoniazid, Azathioprin, Cytosin-Arabinosid, Barbiturate, Reye-Syndrom }\end{array}$ \\
\hline metabolische Erkrankungen & Elektrolytstörungen, diabetisches oder hypoglykämisches Koma, akute Porphyrie, Phäochromozytom \\
\hline systemische Erkrankungen & Sarkoidose, Kollagenosen, insbesondere Neurolupus \\
\hline degenerative Erkrankungen & Adrenoleukodystrophie, Leigh's Enzephalopathie \\
\hline vaskuläre Erkrankungen & zerebraler Infarkt, Vaskulitis, Sinusvenenthrombose, Dissektion \\
\hline Neoplasien & Filiae (Karzinom, Lymphom etc.), paraneoplastische Enzephalitis, Meningeosis \\
\hline
\end{tabular}

Daneben kann es v. a. wiederum bei Kindern, Jugendlichen und jungen Erwachsenen postviral zu einer akuten disseminierten Enzephalomyelitis (ADEM) oder zur Maximalvariante, der akuten hämorrhagischen Leukoenzephalitis (Weston-Hurst-Enzephalitis) kommen [15]. Letztere ist verläuft häufig letal und ist teilweise sehr schwierig von der hämorrhagisch nekrotisierenden Enzephalitis durch Influenzaviren zu unterscheiden.

Die Differenzialdiagnosen virale Enzephalitiden fasst - Tab. 4 zusammen.

\section{Diagnostik bei Verdacht auf eine virale Enzephalitis}

\section{Bildgebung}

Im initialen kranialen Computertomogramm (cCT) bleibt die Bildgebung selbst bei HSV-Typ-1-Enzephalitis häufig unauffällig. Auch bei anderen schweren Enzephalitiden wie der Japan-Enzephalitis finden sich erst nach mehr als 48 Stunden hypodense Veränderungen v. a. im Thalamus und Pulvinar thalami.

\section{Merke}

Bildgebendes Verfahren des 1. Wahl ist somit eine kraniale Kernspintomographie (cMRT), wobei neben den üblichen T2WI, T1WI + Gadolinium und FLAIRSequenzen auch eine SWI oder eine andere Suszeptibilitätsartefakt-sensitive Sequenz zur Anwendung kommen sollten $[2,16]$.
Bereits früh finden sich jedoch Veränderungen im MRT selbst dann, wenn das CCT noch einen Normalbefund aufweist oder nur geringe Auffälligkeiten zeigt. In der Diffusionsgewichtung lassen sich z.B. bei der HSVTyp-1-Enzephalitis bereits innerhalb der ersten 24 Stunden Störungen in typisch betroffenen Regionen des limbischen Systems wie dem Temporallappen oder der Inselrinde nachweisen. Zudem finden sich innerhalb der ersten 48 Stunden nach Beginn der Erkrankung hyperintense Läsionen in frontotemporalen Hirnarealen im FLAIR- und T2-gewichteten Bild. Bei HSVTyp-2-Infektionen lassen sich häufig Veränderungen im Hirnstamm oder auch Myelon mittels MRT nachweisen.

CMV-Infektionen können sowohl eine diffuse Enzephalitis wie auch tumorfaktive Läsionen und eine Ventrikulitis mit ependymalem Gd-Enhancement hervorrufen [8].

Typischerweise sind bei der Infektion mit Flaviviren anders als bei Herpesvirusenzephalitiden der Thalamus, der Pulvinar thalami, die Basalganglien oder auch der Hirnstamm betroffen. Zudem finden sich innerhalb der ersten 48 Stunden nach Beginn der Erkrankung hyperintense Läsionen innerhalb der o.g. im FLAIR- und T2-gewichteten Bild.

Bei West-Nil-Virus- und EV71-Infektionen lassen sich gelegentlich isolierte Veränderungen im Hirnstamm oder auch Myelon mittels MRT nachweisen. Somit ist je nach klinischer Präsentation neben der cMRT auch ein spinales MRT notwendig. 
FAZIT

Die cCT ist bei der viralen Enzephalitis in der Initialphase zumeist unauffällig. Wenn immer möglich, sollte bei V.a. eine virale Enzephalitis eine cMRT veranlasst werden.

\section{Laboruntersuchungen inklusive Liquor}

Laborchemisch kann sich im Serum neben einer Leukozytose eine Erhöhung des CRP ohne Erhöhung des Procalcitonins zeigen [1-3]. Serologische Untersuchungen auf Herpesviridae mit Nachweis von IgG- oder IgM sind in der Akutsituation nicht hilfreich. Ein Titeranstieg von mindestens 4 Stufen innerhalb von 2-4 Wochen nach Beginn der Erkrankung spricht für eine akute spezifische Infektion. Bis dahin sind längst alle Therapiemaßnahmen initiiert.

Im Liquor zeigen sich bei viralen Infektionen eine

- zumeist lymphozytäre Pleozytose (meistens zwi-

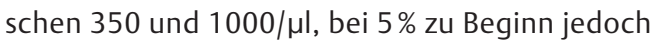
normale Liquorzellzahl),

- ein leicht erhöhtes Protein sowie

- ein allenfalls gering erhöhtes Laktat (bis maximal $4,0 \mathrm{mmol} / \mathrm{I})$.

Aufgrund des hämorrhagischen Aspektes der HSV-Enzephalitis oder auch der Influenzaenzephalitis können Siderophagen nachgewiesen werden. NSE (neuronenspezifische Enolase) und S100-Protein können unspezifisch als Ausdruck des Zelluntergangs erhöht sein.

Merke

Methode der Wahl zum Nachweis einer viralen Infektion des ZNS ist die PCR.

Die Sensitivität und Spezifität liegen z. B. bei HSV-Typ1-Enzephalitis bei 95-100\%.

\section{Merke}

Wichtig ist, dass das Ergebnis des Labors möglichst innerhalb von spätestens 24 Stunden nach Eintreffen des Liquors erhältlich sein sollte.

Die PCR wird zumeist bereits kurz nach Auftreten der ersten Symptome positiv und bleibt in der Regel für bis zu 2 Wochen positiv. In den ersten 24 Stunden sind falsch-negative Befunde möglich. Insofern sollte bei dringendem Verdacht auf eine Enzephalitis mit Herpesviridae und negativer PCR die Lumbalpunktion innerhalb der ersten 3 Tage nach Beginn der Symptome wiederholt werden. Im Verlauf wird die PCR unter Therapie negativ.
Bei anderen Viren als den Herpesviridae zeigen sich im Liquor eine zumeist sehr milde lymphozytäre Pleozytose (meistens zwischen 150 und $1000 / \mu$ ), ein leicht erhöhtes Protein sowie ein allenfalls gering erhöhtes Laktat (bis maximal 4,0 mmol/l).

\section{FAZIT}

Die Polymerase-Kettenreaktion (PCR) ist heute die diagnostische Methode der Wahl bei nichtherpetiformer viraler Enzephalitis. Mit der PCR gelingt der Nachweis auch geringer Mengen viraler DNA oder RNA bei Rötelnvirus-, JC-Virus-, Parvovirus-B19-, Enterovirus- und Masernvirusinfektionen sowie Infektionen mit dem ToskanaVirus. Zudem können Infektionen mit Viren aus der Familie der Herpesviridae (HSV, VZV, EBV, CMV, HHV-6) ausgeschlossen werden.

Mittlerweile kommt zur raschen Klärung der Differenzialdiagnose bei Patienten mit Meningitis und Enzephalitis zunehmend eine Multiplex-PCR zum Einsatz.

\section{Merke}

Mit der Multiplex-PCR ist eine Analyse von bis zu 22 unterschiedlichen Erregern inklusive der häufigsten Viren, Pilze und Bakterien möglich [17]. Die Spezifität liegt bei diesen Verfahren bei >95\%. Am wichtigsten ist jedoch, dass die Gesamt-Turn-around-Zeit für die Diagnostik von 3-7 Tagen auf 4-6 Stunden verkürzt wird, zumindest wenn die Multiplex-PCR innerhäusig im Krankenhaus erhältlich ist.

Bei Flaviviren findet sich lediglich eine leichte lymphozytäre Pleozytose, normale Glukose und leicht erhöhtes Protein. Die Diagnose wird, anders als bei den übrigen Viren, durch den Nachweis von spezifischen IgMAntikörpern in Liquor und/oder Serum bestätigt. Problematisch ist allerdings, dass diese Antikörper über Jahr im Serum persistieren können und es eine starke Kreuzreaktivität unter Flaviviren gibt. Der Nachweis von IgM-Antikörpern im Liquor weist bei Flaviviren die größere Sensitivität und Spezifität auf.

Bei Verdacht auf eine autoimmune Enzephalitis muss daran gedacht werden, dass in erster Linie eine NMDARezeptor-Antikörper-vermittelte limbische Enzephalitis eine Herpesenzephalitis imitieren kann. Andere Antikörper wie Kaliumkanal-Antikörper, Glycin-Rezeptoroder GABA-Rezeptor-Antikörper können ebenfalls ähnliche Bilder verursachen. Eine akute disseminierte Enzephalomyelitis (ADEM) oder eine hämorrhagische Leukenzephalitis (Hurst-Enzephalitis) sind selten, aber können auch von Temperaturerhöhungen, CRP-Anstieg begleitet werden und durch deutliche Liquorverände- 
rungen in Einzelfällen differenzialdiagnostische Probleme bereiten. Im Zweifel ist dann eine stereotaktische Hirnbiopsie notwendig.

\section{FAZIT}

Heutzutage sollte bei dem Verdacht auf eine virale Enzephalitis eine PCR aus dem Liquor mindestens auf die behandelbaren Viren (HSV Typ 1 und 2, CMV, VZV) initiiert werden. Am raschesten erlaubt der Einsatz einer Multiplex-PCR die Identifikation des verursachenden Virus.

\section{Andere Untersuchungen}

Die körperliche Untersuchung muss auf Exantheme, Lymphknotenschwellungen, pulmonale Infektionszeichen oder abdominelle Beschwerden achten. Andere Untersuchungen spielen zumindest in der differenzialdiagnostischen Abklärung keine wesentliche Rolle mehr. Im EEG können sich v.a. teilweise triphasische Potenziale nachweisen lassen. Zudem sollen periodische lateralisierte epileptiforme Entladungen (PLEDs) v.a. bilateral (BIPLEDs) häufig sein. Alle EEG-Befunde sind unspezifisch, können aber die Diagnose unterstützen.

\section{Diagnostik bei Menschen mit HIV-Infektion \\ Bildgebung}

Die cMRT ist in der klinischen Routine wie bei den übrigen viralen Enzephalitiden die Methode der Wahl [10]. Zum einen schließt die cMRT zerebrale opportunistische Infektionen (Zytomegalievirusenzephalitiden, JCVirusinfektionen, Toxoplasma-gondii-Abszesse) und zerebrale Lymphome aus und weist speziell in den T2gewichteten und FLAIR-Sequenzen die HIV-typischen Veränderungen (fleckförmige Echoanhebungen in den hemisphärischen Marklagern und/oder den subkortikalen Kernstrukturen oder flächige, periventrikulär betonte, hyperintense Zonen ohne Entsprechungen in der T1-Gewichtung) nach. Ausgeprägte kernspintomografische Veränderungen sind im Zeitalter der cART selten geworden.

In den weltweit alternden Kohorten (man rechnet damit, dass 2019 über $50 \%$ aller HIV-Positiven älter als 50 Jahre sein werden) sind sie von vaskulären Erkrankungen (subkortikale arteriosklerotische Enzephalopathie) abzugrenzen, was im Einzelfall nicht immer gelingt. Hilfreich kann eine Kernspin-Spektroskopie (MRS) sein, da man mit dieser Methode über reduzierte
N-Acetyl-D-Aspartat-Spiegel eine Beeinträchtigung neuronaler Zellfunktionen nachweisen kann, ebenso über erhöhte Gliazellmarker (Myoinositol, Cholin) eine Zellmembrandysfunktion, eine erhöhte zelluläre Turnover-Rate bzw. eine Gliazellaktivierung.

Merke

Die Befunde der CMRT wie auch MRS sind unter einer CART potenziell reversibel.

\section{Laboruntersuchungen inklusive Liquor}

Unter einer antiretroviralen Therapie normalisieren sich Zellzahl und Gesamtprotein, wobei IgG-Erhöhung und oligoklonale Banden häufig im Liquor persistieren [10]. Die Bestimmung der HI-Viruslast im Liquor sollte immer erfolgen, auch wenn diese nicht immer eindeutig mit klinischen Symptomen oder neuropsychologischen Defiziten korreliert.

Etwa $10 \%$ der HIV-Infizierten zeigen im Liquor ein ViralEscape-Phänomen, d.h. eine Virusreplikation im Liquor trotz effektiver Suppression im Blut oder eine lebhaftere Virusreplikation im Liquor im Vergleich zum Blut. In solchen Fällen soll eine Resistenzanalyse der LiquorVirusvarianten veranlasst werden, um Diskordanzen erfassen und die antiretrovirale Therapie anpassen zu können.

Bei Verdacht auf das Vorliegen einer opportunistischen Infektion sollten eine Multiplex-PCR oder je nach Verdachtsdiagnose andere entsprechende serologische Untersuchungen durchgeführt werden.

\section{Andere Untersuchungen (neuropsychologische Testung)}

Nach dem Ausschluss bzw. unter Berücksichtigung von Komorbiditäten (z.B. auch Hepatitisvirus-C-Ko-Infektion, vorbestehende neurodegenerative oder vaskuläre Demenz) sollten Menschen mit HIV-Erkrankung einer neuropsychologischen Testung entsprechend den Frascati-Kriterien unterzogen werden. Dies bedeutet, dass mindestens 5 Tests absolviert werden müssen, die zeitabhängig sein und Aufmerksamkeit, psychomotorische Geschwindigkeit, mentale Flexibilität und räumlichkonstruktive Fähigkeiten erfassen sollten. Dabei kommen folgende Tests zur Anwendung:

- der Trail-Making Test Form A + B,

- der Digit-Symbol Test,

- der Stroop-Colour Test,

- der Wisconsin Card-Sorting Test,

- der Grooved Pegboard Test sowie

- die Testung der formal-lexikalischen und semantisch-kategoriellen Wortflüssigkeit. 
Sind weniger als 2 von mindestens 5 Tests auffällig, empfiehlt sich eine Kontrolle in 6-12 Monaten und bei pathologischen Resultaten in 2 Tests in 3-6 Monaten. Bei mehr als 2 pathologischen Tests sollten eine ausführlichere neuropsychologische Testung, ein CMRT und eine Lumbalpunktion mit Bestimmung der HI-Viruslast im Liquor sowie ggf. einem Resistenzprofil erfolgen.

\section{FAZIT}

Der Liquorbefund ist bei HIV-assoziierte neurokognitiven Störungen häufig nicht aussagekräftig. Daher sollte, wenn immer die Ressourcen dies zulassen, eine neuropsychologische Untersuchung in regelmäßigen Abständen erfolgen, um subklinische Defizite erkennen zu können.

\section{FALLBEISPIEL}

\section{Fall 3}

Eine 47-jährige Patientin mit afrikanischem Migrationshintergrund stellt sich notfallmäßig aufgrund zuletzt rasch zunehmender kognitiver Defizite vor. Sie habe Schwierigkeiten, sich zu konzentrieren, längere Texte zu lesen und sich neue Sachverhalte zu merken. Es seien keine Vorerkrankungen bekannt. Im Labor findet sich nur eine leichte Leukozytopenie von $3100 / \mu \mathrm{l}$, ansonsten ein Normalbefund. Im EEG zeigt sich eine leichte Allgemeinveränderung, jedoch kein Herdbefund. Neuropsychologisch ist die Patientin sowohl in der Testung der Aufmerksamkeitsfunktionen als auch in der Testung der Merkfähigkeit, der Behaltensleistung wie auch des verbalen Arbeitsgedächtnisses und der psychomotorischen
Geschwindigkeit unterdurchschnittlich. Im cMRT ( Abb. 2) zeigen sich flächige Marklagerveränderungen ohne Gadolinium-Enhancement in der T1WI. Die daraufhin durchgeführte Liquorpunktion weist eine leichte lymphozytäre Pleozytose von $16 / \mu$ l, ein gering erhöhtes Protein sowie positive oligoklonale Banden nach. Im Weiteren ist ein HIV-Test positiv und die Viruslast mit 155000 Kopien/ml stark erhöht. Die CD4 + -Zellen sind auf 275/ $\mu$ l reduziert. Nach Initiierung einer antiretroviralen Kombinationstherapie und Abfall der Viruslast bis unter die Nachweisgrenze bessern sich die Symptome allmählich, und auch die Veränderungen im cMRT sind rückläufig.
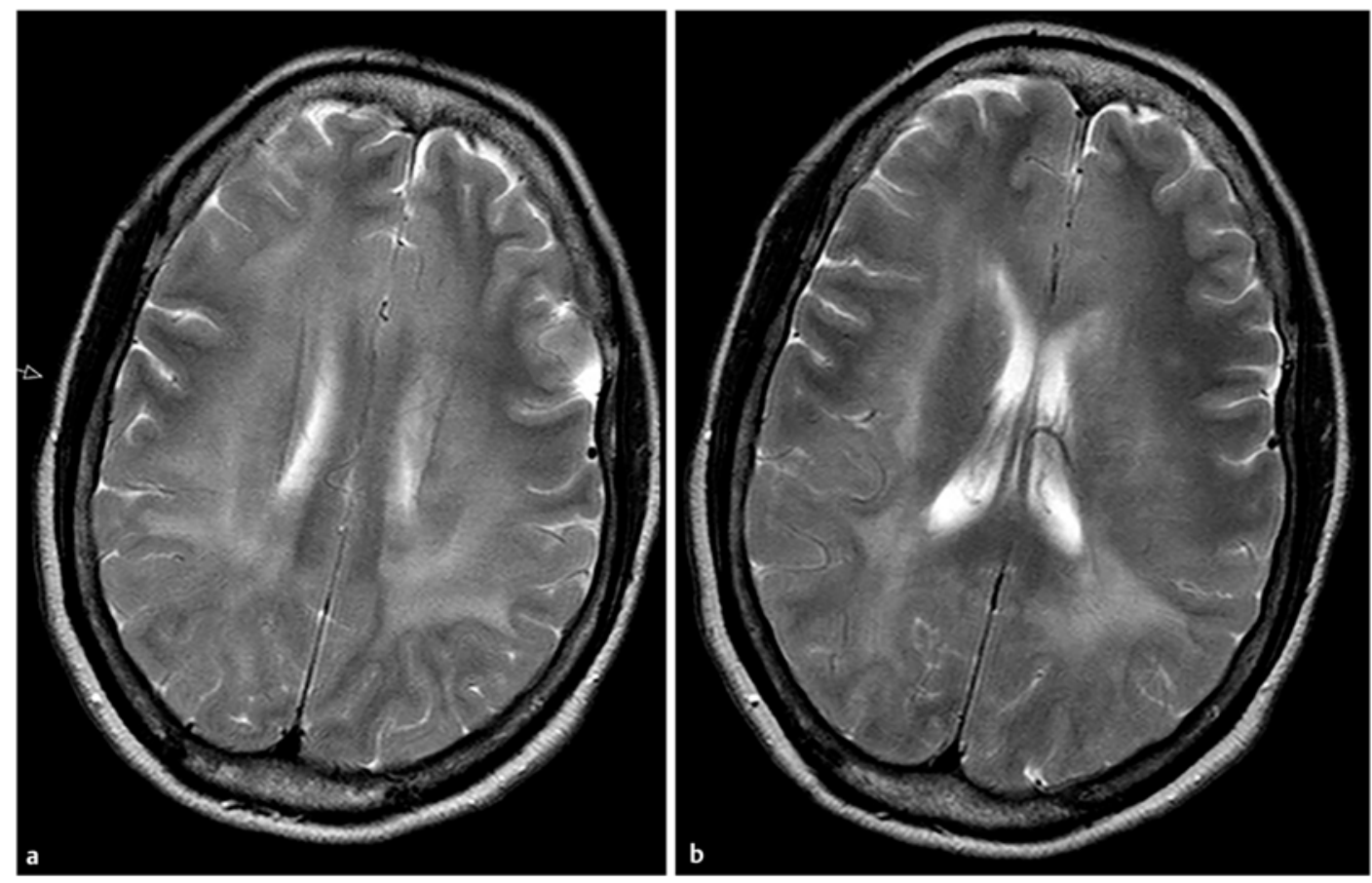

- Abb.2 cMRT einer HIV-Enzephalopathie mit typischen flächigen hyperintensen Veränderungen (T2WI). 


\section{Therapie bei Herpesviridae, Picornaviridae, Orthomyxoviridae, Paramyxoviridae und Flaviviren}

Bei klinischem Verdacht auf eine virale Enzephalitis muss zunächst eine empirische Therapie mit Aciclovir begonnen werden, insbesondere bei V.a. auf eine Infektion mit Herpesviridae. Ein verspäteter Beginn der Therapie verschlechtert die Prognose erheblich.
Bei bekannter Allergie gegen Aciclovir und Nachweis einer positiven PCR auf HSV, VZV oder CMV kann Foscarnet appliziert werden. Aciclovir wird in einer Dosis von $10 \mathrm{mg} / \mathrm{kgKG} 8$-stündlich als i.v. Infusion in 250$500 \mathrm{ml} \mathrm{NaCl} \mathrm{0,9 \%} \mathrm{verabreicht} \mathrm{(Infusionsdauer} \mathrm{mindes-}$ tens 1 Stunde). Die Therapiedauer beträgt 14 Tage. Bei Niereninsuffizienz muss eine Dosisreduktion erfolgen. Die Nierenwerte sollten alle 2 Tage kontrolliert werden. Bei Aciclovir-Allergie bzw. bei Aciclovir-Resistenz kann Foscarnet in einer Dosierung von $90 \mathrm{mg} /$ kgKG alle 12 Stunden (alternativ alle 8 Stunden $60 \mathrm{mg} /$

- Tab. 5 Antivirale Substanzen, die zur Therapie viraler Enzephalitiden in Frage kommen.

\begin{tabular}{|c|c|c|c|}
\hline Wirkstoff (Handelsname) & Empfindliche Erreger & Dosis & Häufigste Nebenwirkungen \\
\hline Aciclovir & HSV, VZV & $3 \times 10 \mathrm{mg} / \mathrm{kgKG} / \mathrm{d}$ i.v. über $1 \mathrm{~h}$ & $\begin{array}{l}\text { Übelkeit und Erbrechen, Absinken hämatologi- } \\
\text { scher Parameter (Anämie, Thrombozytopenie, } \\
\text { Leukozytopenie), reversible Bilirubin- und } \\
\text { Leberenzym-Anstiege, Niereninsuffizienz (auf } \\
\text { ausreichende Flüssigkeitszufuhr achten) }\end{array}$ \\
\hline Brivudin (Zostex) & VZV & $\begin{array}{l}1 \times 125 \mathrm{mg} / \mathrm{d} \text { p. o. über } 7 \text { Tage, } \\
\text { Therapiebeginn mögl. Innerhalb von } \\
\text { 72Std. nach Auftreten der ersten } \\
\text { Effloreszenzen }\end{array}$ & $\begin{array}{l}\text { Übelkeit, BB-Veränderungen, Appetitlosigkeit, } \\
\text { Insomnie, Kopfschmerzen, Schwindel }\end{array}$ \\
\hline Cidofovir (Vistide) & $\begin{array}{l}\text { CMV, in vitro Aktivität } \\
\text { gegen JC-Virus }\end{array}$ & $\begin{array}{l}5 \mathrm{mg} / \mathrm{kgKG} / \mathrm{d} \text { i.v. einmal pro Woche } \\
\text { für } 2 \text { Wochen, } \\
\text { danach } 5 \mathrm{mg} / \mathrm{kgKG} \text { i.v. alle } \\
2 \text { Wochen }\end{array}$ & $\begin{array}{l}\text { Neutropenie, Übelkeit, Alopezie, Proteinurie, } \\
\text { Kreatinin-Anstieg (prophylaktische Gabe von } \\
\text { Probenecid: } 2 \mathrm{~g} 3 \mathrm{~h} \text { vor und } 1 \mathrm{~g} 2 \mathrm{~h} \text { und } 8 \mathrm{~h} \text { nach } \\
\text { Infusion), Uveitis, Senkung des Augeninnen- } \\
\text { drucks }\end{array}$ \\
\hline Famciclovir (Famvir) & HSV, VZV & $\begin{array}{l}\text { 2-3×125-250 mg/d p.o. (bei } \\
\text { Immunsuppression: } 2 \times 500 \mathrm{mg} \text { ) } \\
\text { über } 5-7 \text { Tage }\end{array}$ & $\begin{array}{l}\text { Kreatinin-Anstieg, Kopfschmerzen, Übelkeit, } \\
\text { bei älteren Patienten: Konfusion, Somnolenz, } \\
\text { Desorientierung, Wahnvorstellungen }\end{array}$ \\
\hline Foscarnet (Foscavir) & CMV, HSV & $\begin{array}{l}2 \times 90 \mathrm{mg} / \mathrm{kgKG} / \mathrm{d} \text { i. v. über je } 1-2 \mathrm{~h} \\
\text { für } 14-21 \text { d über ZVK } \\
\text { Erhaltungsdosis: } 1 \times 90-120 \mathrm{mg} / \\
\mathrm{kgKG} / \mathrm{d} \text { i.v. }\end{array}$ & $\begin{array}{l}\text { Nierenfunktionsstörung, in seltenen Fällen } \\
\text { akutes Nierenversagen, Anstieg von Leberen- } \\
\text { zymen, Übelkeit, Durchfall, Blutbildverände- } \\
\text { rungen, Elektrolytstörungen, Parästhesien, } \\
\text { Tremor, Ataxie, Neuropathie, Hypästhesie, } \\
\text { Psychosen, Überaktivität, aggressive Reaktio- } \\
\text { nen, Krampfanfälle, vereinzelt ventrikuläre } \\
\text { Herzrhythmusstörungen (mit Torsades de } \\
\text { pointes, Asystolie), Geschwüre am Penis und } \\
\text { an der Scheide möglich }\end{array}$ \\
\hline Gancyclovir (Cymeven) & CMV & $\begin{array}{l}2 \times \text { tgl. einstündige Tropfinfusion } \\
\text { von } 5 \mathrm{mg} \text { Gancyclovir/kgKG in } \\
12 \text {-stündlichem Abstand für die } \\
\text { Dauer von } 14-21 \text { Tagen } \\
\text { Erhaltungstherapie: } 1 \times \text { tgl. ein- } \\
\text { stündige Infusion von } 5 \mathrm{mg} / \mathrm{kgKG}\end{array}$ & $\begin{array}{l}\text { Knochenmarkdepression, Fieber, Sepsis, Diar- } \\
\text { rhöe, Übelkeit, Schüttelfrost, multiples Organ- } \\
\text { versagen, Azidose, Krämpfe, Schwindel, Syn- } \\
\text { kope, Bewusstseinsstörungen Pruritus, Urtika- } \\
\text { ria, Konjunktivitis, Retinitis u.v. a. }\end{array}$ \\
\hline Oseltamivir (Tamiflu) & Influenza-A-Virus & $2 \times 75 \mathrm{mg} / \mathrm{d}$ p. o. über 5 Tage & Übelkeit, Magenschmerzen \\
\hline $\begin{array}{l}\text { Pleconaril (Picovir, } \\
\text { in Deutschland nicht } \\
\text { erhältlich) }\end{array}$ & Enteroviren, Rhinoviren & $3 \times 200-800 \mathrm{mg} / \mathrm{d}$ p.o. & keine relevanten Nebenwirkungen \\
\hline Valaciclovir (Valtrex) & HSV, VZV & $2-3 \times 0,5-1 \mathrm{~g} / \mathrm{d}$ p.o. & $\begin{array}{l}\text { Kopfschmerzen, Übelkeit, allergische Reaktio- } \\
\text { nen, Blutbild-, Leberwertveränderungen }\end{array}$ \\
\hline Valgancyclovir (Valcyte) & CMV & $\begin{array}{l}2 \times 900 \mathrm{mg} / \mathrm{d} \text { p. o. für } 21 \mathrm{Tage} \\
\text { Erhaltungstherapie: } 1 \times 900 \mathrm{mg} / \mathrm{d}\end{array}$ & $\begin{array}{l}\text { Myelotoxizität, gastrointestinale Neben- } \\
\text { wirkungen; selten: aseptische Meningitis }\end{array}$ \\
\hline Zanamivir (Relenza) & Influenza-A- und B-Virus & 2 Inhalationen à 5 mg/d über 5 Tage & Bronchospasmus \\
\hline
\end{tabular}


kgKG) als einstündige Infusion über 2-3 Wochen verabreicht werden.

In den letzten Jahren häufen sich Fälle mit einer Resistenz gegen Aciclovir. Bei fehlender therapeutischer Antwort auf Aciclovir und gleichzeitiger Persistenz der PCR im Liquor nach mehr als 7 Tagen sollte eine Resistenz erwogen werden und ggf. eine Resistenzbestimmung erfolgen. Sollte diese vorliegen, so ist ein Umsetzen ebenfalls auf Foscarnet notwendig.

- Tab. 5 gibt einen Überblick über die antiviralen Substanzen, die zur Therapie viraler Enzephalitiden in Frage kommen.

Die Effektivität oraler Medikamente wie Valaciclovir ist bei der Enzephalitis mit HSV und VZV nicht getestet, sodass die Gabe oraler Medikamente daher unterbleiben sollte. Eine Verlängerung der intravenösen Therapie durch eine anschließende orale Gabe von Aciclovir oder Valaciclovir erbringt keine Vorteile.

Nach Eintreffen einer negativen PCR auf HSV oder andere behandelbare Herpesviren wie VZV und CMV wird die Therapie mit Aciclovir beendet. Je nach Verdacht und ggf. Nachweis in serologischen Untersuchungen oder der PCR kann mit einer spezifischen Therapie bei bestimmten Viren begonnen werden:

- bei Verdacht auf eine Influenza-A-Virusenzephalitis: Oseltamivir (Tamiflu),

- bei Verdacht auf eine Influenza-B-Virusenzephalitis: Zanamivir (Relenza),

- bei Enteroviren: Plecoranil (Picovir, in Deutschland nicht erhältlich),

- bei Flaviviren: Therapieversuch mit Favipravir (Avigan) oder Brincidofovir. Beide Medikamente sind in Europa noch nicht zugelassen.

Da es nach wie vor keine Studien gibt, die die Gabe von Kortikosteroiden bei der viralen Enzephalitis belegt, ist eine adjuvante Kortisongabe derzeit nicht zu empfehlen. Bei einem malignen Hirnödem kann eine Hemikraniektomie indiziert sein, selten auch eine bilaterale Hemikraniektomie.
FAZIT

- Bei Verdacht auf eine virale Enzephalitis sollte unverzüglich mit Aciclovir mindestens bis zum Eintreffen der PCR begonnen werden.

- Eine adjuvante Kortisongabe solle auch dann unterbleiben, wenn ein Hirnödem klinisch oder radiologisch vorliegt.

- Bei progredientem Hirndruck kommt auch bei viralen Enzephalitiden eine uni- oder sogar bilaterale Hemikraniektomie in Frage.

\section{Outcome und Prognose}

Unter rasch initiierter intravenöser Gabe von Aciclovir überleben $80 \%$ der Patienten mit einer HSV-Typ-1-Enzephalitis. Nach Ende der Akutphase haben jedoch ca. $50 \%$ der Patienten neurologische Residuen und kognitive Defizite.

Die Letalität und Morbidität nicht-herpetiformer viraler Enzephalitiden hängt sehr vom Erreger ab. Während Infektionen mit Adeno- und Enteroviren teilweise sehr blande ablaufen können, führen Infektionen mit dem Japan-Enzephalitisvirus oder dem West-Nil-Virus zu einer hohen Letalität (25\%) und sehr häufigen Residuen (>30\%).

\section{Präventive Maßnahmen}

Die Impfung gegen Viruserkrankungen ist präventiv entsprechen den Vorgaben der ständigen Impfkommission [19] bei folgenden Viren sinnvoll:

- Poliomyelitis, Masern, Mumps und Röteln.

- Weiterhin sind nach jeweiliger Indikation auch Impfungen gegen Influenza, FSME, Hepatitis B, Gelbfieber, Tollwut und Adenovirus Typ 4 und 7 verfügbar.

- Darüber hinaus sind Vakzine gegen Flaviviren (z. B. West-Nil-Virus, Japan-Enzephalitisvirus) in der Entwicklung bzw. Anwendung. Bei der Japan-Enzephalitis gibt es mittlerweile eine ganze Reihe zugelassener Vakzine mit unterschiedlichen Vor- und Nachteilen; bei entsprechenden Reisevorhaben wird die Impfung ausdrücklich empfohlen.

Gegen das Dengue-Virus ist ebenfalls mittlerweile ein Impfstoff erhältlich, wobei die Impfung kritisch gesehen werden muss. Nach durchgemachter Infektion mit einem Serotyp besteht eine lebenslange Immunität für den infizierenden Serotyp und eine ca. 1-2 Jahre andauernde Kreuzimmunität für die anderen Serotypen. Bei einer Zweitinfektion ist das Risiko, einen schweren Krankheitsverlauf zu entwickeln, deutlich höher mit ca. 0,5-2\% (,antibody-dependent enhancement“). Die Zulassung der Impfung mit Dengvaxia ist daher beschränkt auf Personen im Alter von 9-45 Jahren, die in einem Endemiegebiet leben und zuvor bereits eine la- 


\section{FALLBEISPIEL}

\section{Fall 4}

Eine 80 Jahre alte Patientin wird mit einem Exanthem periorbital rechts sowie Doppelbildern per NAW eingeliefert. In der körperlichen Untersuchung finden sich ein Zoster ophthalmicus rechts sowie eine komplette N.III-Parese und ein leichter Meningismus. Ab dem 8. März wird eine Therapie mit Aciclovir $3 \times 10 \mathrm{mg} / \mathrm{kgKG}$ unter regelmäßiger Kontrolle der Nierenwerte gestartet. Das CMRT ( $\triangleright$ Abb. 3 ) weist ein starkes Gadolinium-Enhancement der gesamten Meningen nach.
Im Liquor finden folgende Befunde:

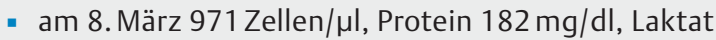
$68 \mathrm{mg} / \mathrm{dl}, \mathrm{VZV}-\mathrm{PCR}$ positiv,

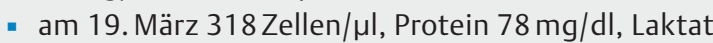
$23 \mathrm{mg} / \mathrm{dl}, \mathrm{VZV}-\mathrm{PCR}$ positiv und

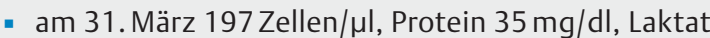
$19 \mathrm{mg} / \mathrm{dl}, \mathrm{VZV}-\mathrm{PCR}$ negativ.

Die Symptome bessern sich vom 8. März bis zum 19. März nicht wesentlich, sodass die Therapie mit Aciclovir auch aufgrund des Liquorbefundes und des Nachweises der positiven PCR bei der Kontrollpunktion noch bis zum 31. März fortgesetzt wird.
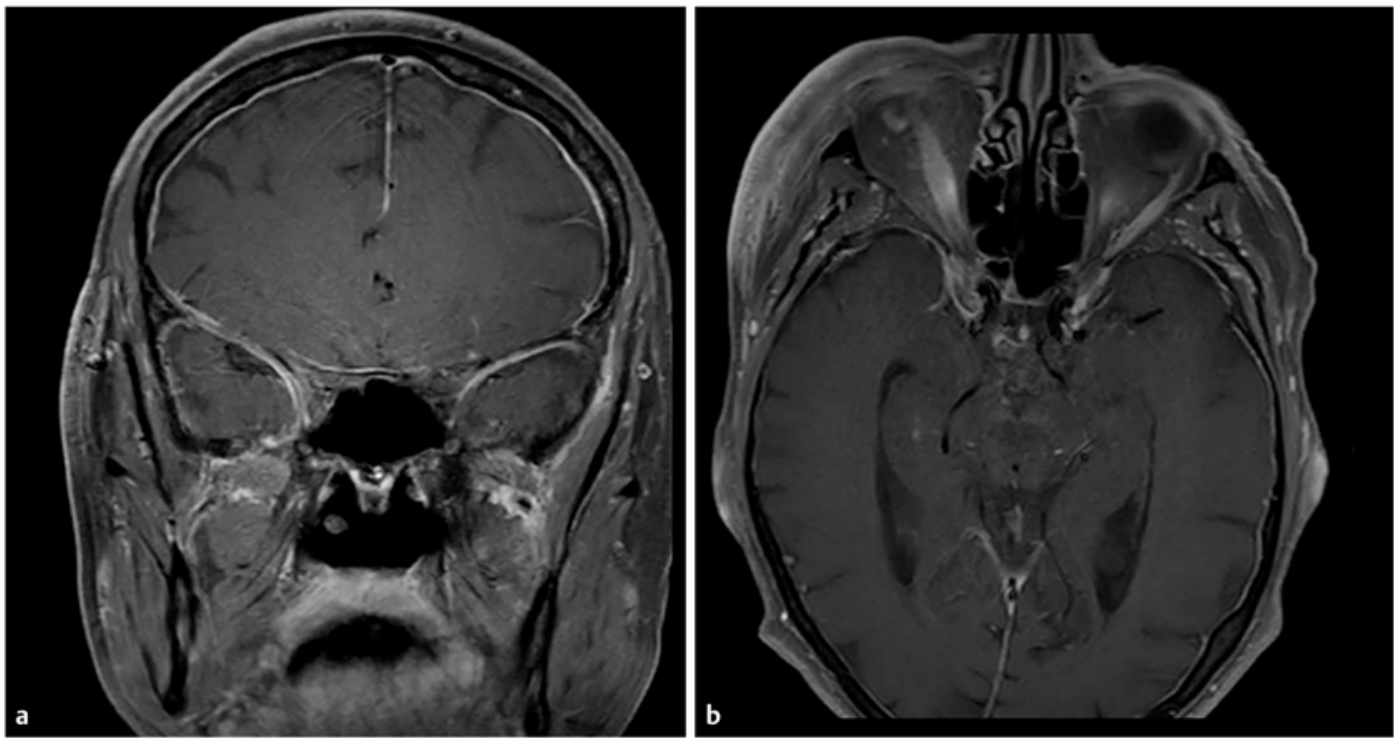

- Abb. 3 cMRT einer Patientin mit VZV-Meningoenzephalitis. Meningeales Gadolinium-Enhancement v. a. in der koronaren T1WI mit Gd (links), weniger in der axialen Sequenz zu erkennen (rechts).

borbestätigte Dengue-Infektion durchgemacht haben. Es besteht keine Indikation für die Anwendung bei Reisenden.

\section{Therapie bei HIV-assoziierten neurokognitiven Störungen}

HIV-assoziierte neurokognitive Störungen werden durch die antiretrovirale Therapie (CART) behandelt, die sich möglichst nach dem CPE-Score $[10,20]$ richten sollte. Inwieweit dies jedoch auch nach wie vor unter Einsatz neuester antiretroviraler Therapien gilt, ist Gegenstand der Diskussion [21]. Es ist sinnvoll, bei Auftreten multiresistenter Virusvarianten im Blut auch im Li- quor entsprechende Untersuchungen durchzuführen, falls die Kopienzahlen in diesem Kompartiment ausreichend sind (für die meisten Laboratorien gilt: mindestens $100 \mathrm{c} / \mathrm{ml}$ ). Als adjuvante Therapie ist Memantin von der FDA - nicht jedoch in Deutschland - zugelassen. Der Therapieeffekt von Memantin ist allerdings nicht unwidersprochen. 


\section{FAZIT}

HIV-assoziierte neurokognitive Störungen sollten durch eine Optimierung der CART behandelt werden. Eine Lumbalpunktion sollte zum Ausschluss konkurrierender opportunistischer Infektionen und mit der Frage nach einem „viral Escape“ des HI-Virus erfolgen.

\section{KERNAUSSAGEN}

- Virale Infektionen des zentralen Nervensystems sind in Westeuropa zwar vergleichsweise selten, gehören aber weltweit zu den häufigsten $\mathrm{Er}$ krankungen, die zu einem Leben mit Behinderung führen.

- Die rechtzeitige Diagnose und der rasche Beginn einer Therapie sind für die Prognose von essenzieller Bedeutung unerlässlich, jedoch kann die Differenzialdiagnose viraler Enzephalitiden bezüglich der Erreger sehr aufwendig sein.

- Die häufigsten Erreger einer Enzephalitis bei Erwachsenen sind in Deutschland weiterhin die Herpesviridae, allen voran das Herpes-simplexVirus Typ 1.

- Im Blick zu behalten sind jedoch ebenfalls die sog. Emerging Viruses, die aufgrund des Klimawandels und des regen Reiseaufkommens immer häufiger in Europa anzutreffen sind und bei denen u. a. eine schwerwiegende neurologische Mitbeteiligung drohen kann.

- Die Prävalenz neurokognitiver Defizite bei Patienten mit HIV-Infektion (Neuro-Aids) ist hingegen seit Einführung der antiretroviralen Kombinationstherapien (cART) stark zurückgegangen.

- Letalität und Morbidität viraler Enzephalitiden hängen sehr vom Erreger ab und können recht mild ablaufen, aber auch mit gravierenden Folgen vergesellschaftet sein.

- Die Impfung gegen Viruserkrankungen ist präventiv entsprechend den Vorgaben der Ständigen Impfkommission des Robert Koch-Instituts (STIKO) gegen zahlreiche Viren möglich.

\section{Interessenkonflikt}

\section{Erklärung zu finanziellen Interessen}

Forschungsförderung erhalten: nein; Honorar/geldwerten Vorteil für Referententätigkeit erhalten: ja; Bezahlter Berater/interner Schulungsreferent/Gehaltsempfänger: ja; Patent/Geschäftsanteile/Aktien (Autor/Partner, Ehepartner, Kinder) an Firma (Nicht-Sponsor der Veranstaltung): nein; Patent/Geschäftsanteile/Aktien (Autor/Partner, Ehepartner, Kinder) an Firma (Sponsor der Veranstaltung): nein.

Erklärung zu nichtfinanziellen Interessen

1. Deutsche Gesellschaft für Neurologie

2. Deutsche Gesellschaft für klinische Neurophysiologie

3. Arbeitskreis neurologische Intensivmedizin

4. DGNANI

5. DMKG

6. ALNK

7. American Academy of Neurology

8. European Academy of Neurology

\section{Autorinnen/Autoren}

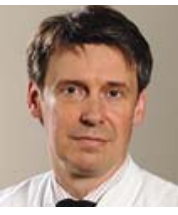

\section{Matthias Maschke}

Prof. Dr. med., Facharzt für Neurologie und Zusatzbezeichnungen Neurologische Intensivmedizin und Geriatrie; 2003 Habilitation. 1995-2006 tätig an der Neurologischen Universitätsklinik Essen, zuletzt als leitender Oberarzt. 2002-2003 Forschungsaufenthalt in der Division of Kinesiology and Neuroscience Program, University of Minnesota, Minneapolis, USA. Seit 2006 ist er Chefarzt der Klinik für Neurologie und Neurophysiologie mit überregionaler Stroke Unit und Frührehabilitation am Brüderkrankenhaus Trier. Zudem ist er Vorsitzender des Demenzzentrums für die Region Trier e.V. und Vorstandsmitglied der DGNANI e.V.

\section{Korrespondenzadresse}

\section{Prof. Dr. med. Matthias Maschke}

Klinik für Neurologie und Neurophysiologie

Brüderkrankenhaus Trier

Nordallee 1

m.maschke@bk-trier.de

Wissenschaftlich verantwortlich gemäß Zertifizierungsbestimmungen

Wissenschaftlich verantwortlich gemäß Zertifizierungsbestimmungen für diesen Beitrag ist Prof. Dr. med. Matthias Maschke, Trier. 


\section{Literatur}

[1] Parpia AS, Li Y, Chen C et al. Encephalitis, Ontario, Canada, 2002-2013. Emerg Infect Dis 2016; 22: 426-432. doi:10.3201/eid2203.151545

[2] Maschke M. Virale Entzündungen des ZNS. In: Diener HC, Gerloff C, Dieterich M, Hrsg. Therapie und Verlauf neurologischer Erkrankungen. 7. Aufl. Stuttgart: Kohlhammer Verlag; 2017

[3] Koskiniemi M, Rantalaiho T, Piiparinen $\mathrm{H}$ et al. Infections of the central nervous system of suspected viral origin: a collaborative study from Finland. J Neurovirol 2001; 7: 400404

[4] Mailles A, Stahl JP. Steering Committee and Investigators Group. Infectious encephalitis in france in 2007: a national prospective study. Clin Infect Dis 2009; 49: 1838-1847. doi:10.1086/648419

[5] Robert-Koch Institut. Epidemiologisches Bulletin Nr. 46/ 2019. Im Internet: (Stand: 16.01.2020) https://www.rki.de/ DE/Content/Infekt/EpidBull/Archiv/2019/Ausgaben/46_19. pdf?__blob=publicationFile

[6] Singh TD, Fugate JE, Hocker $S$ et al. Predictors of outcome in HSV encephalitis. J Neurol 2016; 263: 277-289. doi:10.1007/s00415-015-7960-8

[7] Petersen LR, Brault AC, Nasci RS. West Nile virus: review of the literature. JAMA 2013; 310: 308-315. doi:10.1001/jama.2013.8042

[8] Maschke M, Kastrup O, Diener HC. CNS manifestations of cytomegalovirus infections: diagnosis and treatment. CNS Drugs 2002; 16: 303-315

[9] Pruitt AA. Infections of the cerebellum. Neurol Clin 2014; 32: 1117-1131. doi:10.1016/j.ncl.2014.07.009

[10] Arendt G, Hahn K, Maschke M et al. Neues bei HIV und Neuro-Aids. Akt Neurol 2015; 42: 445-455. doi:10.1055/s0035-1552692

[11] Antinori A, Arendt G, Becker JT et al. Updated research nosology for HIV-associated neurocognitive disorders. Neurology 2007; 69: 1789-1799. doi:10.1212/01. WNL.0000287431.88658.8b

[12] The UK Collaborative HIV Cohort (CHIC) Study Steering Committee. HIV-associated central nervous system diseases in the recent combination antiretroviral therapy era. Eur | Neurol 2011; 18: 527-534. doi:10.1111/j.14681331.2010.03291.x
[13] Tan IL, Smith BR, von Geldern G et al. HIV-associated opportunistic infections of the CNS. Lancet Neurol 2012; 11: 605-617. doi:10.1016/S1474-4422(12)70098-4

[14] Armangue T, Spatola M, Vlagea A et al. Frequency, symptoms, risk factors, and outcomes of autoimmune encephalitis after herpes simplex encephalitis: a prospective observational study and retrospective analysis. Lancet Neurol 2018; 17: 760-772. doi:10.1016/S1474-4422(18)30244-8

[15] Pohl D, Alper G, Van Haren K et al. Acute disseminated encephalomyelitis: Updates on an inflammatory CNS syndrome. Neurology 2016; 87: (Suppl. 02): S38-45. doi:10.1212/ WNL.0000000000002825

[16] Kastrup O, Wanke I, Maschke M. Neuroimaging of infections of the central nervous system. Semin Neurol 2008; 28: $511-$ 522. doi: $10.1055 / \mathrm{s}-0028-1083688$

[17] Long F, Kong M, Wu S]. Development and validation of an advanced fragment analysis-based assay for the detection of 22 pathogens in the cerebrospinal fluid of patients with meningitis and encephalitis. Clin Lab Anal 2019; 33: e22707. doi:10.1002/jcla.22707

[18] Schulte EC, Sauerbrei A, Hoffmann D et al. Acyclovir resistance in herpes simplex encephalitis. Ann Neurol 2010; 67: 830-833. doi:10.1002/ana.21979

[19] Robert-Koch Institut. STIKO-Empfehlungen. Im Internet: (Stand: 16.01.2020) https://www.rki.de/DE/Content/Kommissionen/STIKO/Empfehlungen/

[20] Letendre S, Marquie-Beck J, Capparelli E et al. Validation of the CNS Penetration-Effectiveness rank for quantifying antiretroviral penetration into the central nervous system. Arch Neurol 2008; 65: 65-70. doi:10.1001/archneurol.2007.31

[21] Heaton RK, Franklin DRJr, Deutsch R et al. Neurocognitive change in the era of HIV combination antiretroviral therapy: the longitudinal CHARTER study. Clin Infect Dis 2015; 60: 473-80. doi:10.1093/cid/ciu862

Bibliografie

DOI https://doi.org/10.1055/a-0936-1226

Neurologie up2date 2020; 3: 23-39

(c) Georg Thieme Verlag KG Stuttgart · New York ISSN 2511-3453 


\section{Punkte sammeln auf CME.thieme.de}

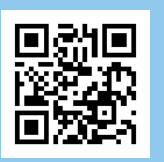

Diese Fortbildungseinheit ist in der Regel 12 Monate online für die Teilnahme verfügbar.

Den genauen Einsendeschluss finden Sie unter https://cme.thieme.de.

Sollten Sie Fragen zur Online-Teilnahme haben, finden Sie unter https://cme.thieme.de/hilfe

eine ausführliche Anleitung. Wir wünschen viel Erfolg beim Beantworten

der Fragen!

Unter https:|/eref.thieme.de/CXDA8ZA oder über den QR-Code kommen Sie direkt zur Startseite des Wissenstests.

VNR 2760512020158724571

\section{Frage 1}

Welche Aussage trifft zu?

A Die häufigste virale Enzephalitis weltweit ist die JapanEnzephalitis.

B Infektionen mit Zika-Viren sind in Deutschland häufig.

C Die Neuinfektionsrate mit dem humanen Immundefizienzvirus (HIV) nimmt in Deutschland weiterhin drastisch zu.

D Zytomegalievirus (CMV)-Infektionen treten ausschließlich bei immuninkompetenten Patienten auf.

E Infektionen des Zentralnervensystems mit Herpes-simplexVirus Typ 1 sind zumeist harmlos.

\section{Frage 2}

Welches sind die Kriterien für ein HIV-assoziiertes neurokognitives Defizit?

A Halte- und Intentionstremor

B Orientierungsstörungen

C isolierte Merkfähigkeitsstörungen

D die Frascati-Kriterien

E die Framingham-Klassifikation

\section{Frage 3}

Welches ist die häufigste virale Enzephalitis in Deutschland?
A HSV-Typ-1-Enzephalitis (Herpes-simplex-Typ-1-Enze- phalitis)
B VZV-Enzephalitis (Varicella-zoster-Virus)
C CMV-Enzephalitis (Zytomegalievirus)
D EBV-Enzephalitis (Epstein-Barr-Virus)
E HHV6-Enzephalitis (humanes Herpesvirus Typ 6)

\section{Frage 4}

Gegen welches Virus ist bei entsprechendem Reisevorhaben eine Impfung möglich und sinnvoll?
A Dengue-Virus
B Usutu-Virus
C Japan-Enzephalitisvirus
D West-Nil-Virus
E Zika-Virus

\section{Frage 5}

Nur eine der folgenden Aussagen ist richtig. Welche?

A HIV-Infektionen führen heutzutage nicht mehr zu neurologischen Symptomen.

B Die Anzahl der Infektionen mit Emerging Viruses (wie West-Nil-Virus) nimmt in Europa zu.

C Hepatitisviren führen nicht zu neurologischen Erkrankungen.

D Mit Dengue-Viren kann man sich nur in Südamerika und Afrika infizieren.

E Präventive Impfungen gegen Viruserkrankungen sind bei Erwachsenen nicht sinnvoll.

\section{Frage 6}

Eine der folgenden Aussagen ist falsch. Welche?

A Die Antikörperdiagnostik ist bei Herpesviridae sehr spezifisch und diagnoseweisend.

B Wenn möglich, sollte eine Multiplex-PCR (PCR = Polymerase Chain Reaction) zum Einsatz kommen.

C Goldstandard in der Diagnostik der HSV-Typ-1-Enzephalitis ist die positive PCR aus dem Liquor.

D Bei HIV (= humanes Immundefizienzvirus) sollte bei neurologischen Störungen die Viruslast auch im Liquor bestimmt werden.

E Bei Flaviviren erfolgt der Nachweis am besten über die Bestimmung der IgM-Antikörper im Liquor

\section{Frage 7}

Welche Aussage zur Therapie viraler Erkrankungen ist richtig?

A West-Nil-Virus-Infektionen werden mit Foscarnet behandelt.

B Meningoenzephalitiden aufgrund von VZV (= Varicellazoster-Virus) werden mit Aciclovir $3 \times 10 \mathrm{mg} / \mathrm{kgKG} / \mathrm{d}$ therapiert.

C Epstein-Barr-Virus (EBV)-Infektionen werden immer mit Brivudin behandelt.

D Dengue-Virusinfektion profitieren von der Gabe von Ganciclovir.

E Herpes-simplex-Virusenzephalitiden werden mit Valaciclovir nachbehandelt. 


\section{Punkte sammeln auf CME.thieme.de}

\section{Fortsetzung ...}

\section{Frage 8}

Welches Medikament sollte bei Allergie gegen Aciclovir und Vorliegen einer Herpesenzephalitis zum Einsatz kommen?
A Brivudin
B Valaciclovir
C Foscarnet
D Cidofovir
E Ganciclovir

\section{Frage 9}

Welche Aussage zu Infektionen mit Zytomegalievirus (CMV) ist falsch?
A Die Infektion kann zu einer Ventrikulitis führen.
B Tumorfaktive Läsionen können vorkommen.
C CMV-Infektionen treten nur bei immuninkompetenten Patienten auf.
D Eine Meningoenzephalitis ist die häufigste Manifestation.
E Eine Myelitis ist ebenfalls möglich.

\section{Frage 10}

Welches Virus führt typischerweise nicht zu einer medialen Enzephalitis mit dominanter Beteiligung des Thalamus und Hirnstamms?
A West-Nil Virus
B Usutu-Virus
C Japan-Enzephalitisvirus
D Zika-Virus
E Herpes-simplex-Virus Typ 1 